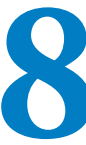

\title{
Are female academics more research resilient? Evidence from South India's engineering institutions
}

Venkat Bakthavatchaalam, University of Plymouth, UK Maria Jose Sa, Centre for Research in Higher Education Policies (CIPES), Portugal

E. Baburaj, Karpagam College of Engineering, India Mike Miles, University of Plymouth, UK

\section{Introduction}

This study explores the various factors that influence female academics to be able to conduct research and publish in a developing country scenario, specifically India. This ongoing study focuses on Sustainable Development Goal (SDG) 4: Quality Education, SDG5: Gender Equality and SDG8: Decent Work and Economic Development by looking at South India's engineering academics, with the main purpose of identifying and exploring various factors influencing their employment and Research Productivity (RP). 
The study uses a qualitative approach to understand the perceptions of the academics regarding the various hurdles faced by female academics in their research and the mechanisms they use to overcome them. Interviews were conducted with both male and female academics. Content analysis was used for data analysis. This research builds upon the quantitative results from a previous study on this topic by Bakthavatchaalam (2018), who identified that, as in many developing countries, Indian female academics face a considerable number of disadvantages, such as economic pressures, family duties, not being able to access adequate resources and interestingly, social and cultural factors vis-avis their male peers. Even with these disadvantages, the study revealed, rather surprisingly, that female academics had similar levels of research productivity with their counterpart male academics. This research examines how female academics are managing to achieve this level of productivity.

\section{Literature review}

Conducting research, advancing knowledge and publishing the results are at the heart of any higher education institution (HEI). Academic papers have become an important indicator of academics' productivity within HEls. Publications are seen as an essential element in measuring and influencing academics' carrier progression, a department's performance, individual academic distinction and institutional excellence, as well as an indicator for acquiring grants and securing funding (Carayol and Matt, 2006; Fox, 2005; Nygaard, 2015). Since academics are the fundamental building blocks on which institutional research is based (Enders, 2007), institutions need to identify the factors that influence academics' research; to invest in the factors that increase it; and to eliminate any impeding factors.

Research Productivity (RP) is a quantifiable measure of conducting and publishing research (Abramo and D'Angelo, 2014; Altbach, 2015). RP is an accumulation of different activities, including publishing papers at the national and international levels, producing books, chapters and monographs, securing grants, supervising research students, serving as a peer reviewer, being an editorial board member, giving lectures as a guest speaker, contributing to national and international level committees, and filing patents (Horodnic and Zait, 2015; Wootton, 2013).

$\mathrm{RP}$ is an effect with various and complex determinants (Ramesh Babu and Singh, 1998). Academics' motivation to conduct research and publish results is 
influenced by a complex array of factors, including their demographics, such as age, sex, marital status, qualifications and the composition of academic staff in their department (Aksnes, 2012; Adams and Clemmons, 2009; Ebadi and Schiffauerova, 2016; Oshagbemi, 2000). There are also personal and professional factors, such as motivation and self-efficacy, time allocated for different duties, pay scales, institutional position and promotion opportunities (Callaghan, 2015; Horodnic and Zait, 2015; Tien and Blackburn, 1996). Governing bodies, national and international educational policies and how they evolve (Amaral et al., 2009; Diogo, 2015; Frolich and Caspersen, 2017; Vlasceanu and Hancean, 2015), along with the Changing Academic Environment (CAE) (Arimoto et al., 2013; Bakthavatchaalam et al., 2019; Machado-Taylor et al., 2017; Rani, 2010) may all have an influence.

When focusing on genders' RP, several studies have pointed to the lower RP of female academics compared with their male counterparts and have explored the causes and consequences of this difference. Lariviere et al. (2013), in their bibliometric study, comment that men having a higher RP is a worldwide phenomenon and they add that women have a lower first authorship. Aksnes et al. (2011) and Prpic (2002) report that for all age groups, male academics have a higher research output. However, in a later study, Rorstad and Aksnes (2015) suggest that men publish more only until fifty-five to fifty-nine years of age, after which women overtake them. Even though male academics are reported to have higher RP, female peers are reported to have a higher job satisfaction (Katoch, 2012; Smeby and Try, 2005).

Astegiano et al. (2019) point out the prevalence of male-oriented research environments, especially in STEM fields of study, generating a range of socio-psychological hurdles for female academics. This creates an environment where female academics have to outperform men so that their research potential or contribution is noticed. Similarly, Ozkanlı et al. (2009) and Harley (2003) point out that the higher education (HE) system and its structure favour norms that disadvantage women in being recruited, for instance, for top institutional posts and the allocation of various resources. The sociocultural system also impedes female academics by assuming their pivotal centrality within the family and domestic setting, thus undervaluing their role in a scientific and public setting. Usually, the lower level of female academics' RP is ascribed to them having to balance parenting and work roles. However, Aiston and Jung (2015) comment that it is not just family-related factors that decrease female academics' RP but, importantly, it is the systemic and structural discriminatory practices within academia that disadvantage them. 
Reduced mobility for data collection, networking and other research tasks (Abramo et al., 2013), academic gatekeepers and paper reviewers undervaluing women's scientific contributions are all factors reported to be disadvantaging females (Knobloch-Westerwick et al., 2013). Parenting and having young children are reported by Hunter and Leahey (2010) and Richards (2006) as predominant factors that limit female academics' RP and their academic career advancement.

Men are widely reported as being better at using their networks for their research compared to women who find it more difficult to engage in networking. Networks range from professional and business groups, alumni associations and just simply talking with their seniors, which could enhance job opportunities and the ability to access resources and increase their social capital (Klasen and Pieters, 2012; Paksi and Tardos, 2018; Sarkar et al., 2019). This absence of networking also affects female academics' collaboration patterns. This can be seen in Huang (2019) and Lee and Bozeman (2005) who revealed the lack of international collaboration and publications of female academics. Cultural prejudices associated with collaborating with academics of the opposite sex are also seen to negatively impact female academics in some countries, whereas this situation is seen to have less influence on male academics (Abramo et al., 2013).

Along with the cited difficulties, Fox (2005) maintains that there is a presupposition of how RP and being an active researcher varies between genders. The perception is that an active and productive academic is either a married man or a woman with no husband or children. There also appears to be a lack of understanding of the gender differences and shortage of policies and practices for building equity (Acker, 2006).

Especially in STEM, the underrepresentation of female academics is seen to be an important reason for their lower RP (Aguinis et al., 2018). It is common across most nations to have gender inequality in STEM, with the number of males being significantly higher than that of females, with India being no exception. Even though there has been an effort to increase female representation in STEM, this has been slow, especially in fields where there is a high gender bias (Aguinis et al., 2018; Astegiano et al., 2019).

Other reasons cited for the disadvantages female academics face include females being drafted for more teaching-oriented duties (Bosanquet, 2017; Suitor et al., 2001); the absence of day-care and child-care facilities in institutions; and a denial of the existence of gender-related issues in institutions (Gupta, 
2017). Also, women are culturally considered for more pastoral 'academic mommies' roles (Ropers-Huilman, 2002). Inequality in the allocation of time and resources (Xie and Shauman, 2004) are proven factors that have limited women's research participation and consequently their RP. However, a recent study by Bakthavatchaalam (2018) found no difference between the time spent for teaching, research and administrative duties between male and female academics.

Overall, despite women's high level of educational attainment, the general social structure and assumptions of gender roles continue to flow into academia. Gender equality in STEM is a hotly debated topic and an essential element in achieving the SDGs (UNESCO, 2017). STEM education, especially engineering, is expected to play a major role in the achievement of the SDGs. While it is encouraging to see an increasing number of women choosing STEM-related subjects, Holman et al.(2018) and West et al. (2013), based on their analysis of eight million papers, comment that even though the gender gap seems to be closing and that there is a projected increase in the number of female STEM learners, gender parity will not be achieved in specialist science, physics and mathematics subjects within this century. This is rather alarming, especially in regard to achieving SDG5.

Looking at the first authorship of papers in India, Thelwall et al. (2019) concluded, in that year, that there were 50 per cent more male first authors than females in scientific publications. It was also noted that male academics preferred to conduct research in 'things-oriented' fields, whereas female academics chose to conduct research in 'human-oriented' fields.

It is critical to identify, understand and analyse the various difficulties faced by female academics in STEM disciplines in order to overcome them. UNESCO (2017) highlighted a range of barriers to women pursuing STEM, such as biological factors, neuroscience and brain structures. However, this research focuses on the influence of social, economic, cultural, institutional and familyoriented factors. It is essential that policies not only address these issues but also recognize the historical bias that has caused this gender imbalance in STEM in the first place. Furthermore, rather than having generic gender policies, these should be designed for distinct academic disciplines.

With respect to female academics' resilience, Richman et al. (2011) advocate that in mathematics-intensive fields they are becoming more successful at coping effectively, even though they are a minority in traditional male-dominated fields. 
The authors further postulate that helpful female role models, family support and social support outside of work enable women to build resilience. Even more interesting was the finding that women in engineering fields are less sensitive to experiencing a 'social identity threat' than female academics from other genderbalanced fields. How this work reflects the scenario in South India is open to question.

Bakthavatchaalam (2018), in his research on the RP of south Indian engineering academics, identifies and quantifies that, irrespective of marital status and age, there was no significant statistical difference in RP between male and female academics. This is a surprising result that challenges established literature. This paper builds upon the work of Bakthavatchaalam (2018) and explores how, despite the various barriers female academics face, they are capable of overcoming them and succeeding in being equally productive as men.

\section{Need for the research}

Recent publications, including Sarkar et al. (2019), Deshpande (2019) and IMF (2015), are generic in addressing female participation across professions, as well as in low-skilled and low-paid jobs. Whereas this research looks into the academic participation of women, particularly in STEM professions. This is the first of this kind of research to be conducted in South India and it attempts to better understand female academics' resilience. The findings should be of use in other developing countries where female academics might face similar issues. It should also help to address the challenges of productive job creation and the goal of achieving gender equality and decent work for all.

This research is important and timely, particularly considering the rapid expansion of the Indian Higher Education (HE) system. Currently, there are 37.4 million enrolled students, 48.6 per cent of whom are female. In terms of the HEls (Higher Education Institutions), in 2018-19, a total of 993 universities, 39,931 colleges and 10,725 stand-alone institutions were operational in India (AISHE, 2019). The rapid increase in the HE system is evident from the fact that over the last eighteen years, the number of HEls increased by 230 per cent, the number of students by 311 per cent and the number of academics by 269 per cent (UGC-Report, 2018). Of these academics, 42 per cent are female, emphasising the importance of this research. Also, as Aguinis et al. (2018) stated, this female focus is a new area of research in India. Also, as we attempt to achieve SDGs 4, 5 and 8 , it is essential that we explore and understand the various issues faced 
by female academics in engineering, along with their resilience mechanisms. So, building on the literature and the need for this research, this paper seeks to answer the following questions:

1. What are the various factors that uniquely influence female academics' research productivity?

2. How do sociocultural factors in India affect different genders' RP?

3. How are female academics able to overcome the barriers to RP stemming from social and cultural factors in South India?

\section{Methodology}

This study uses a qualitative approach, given that its main purpose is to identify and understand the impact of cultural and social factors on the RP of male and female academics in South India. Qualitative methods are more suited to grasp and interpret the meanings of the results for the chosen research questions (Denzin and Lincoln, 2011; Merriam and Tisdell, 2009; Willig, 2001). This is a privileged way of collecting data about an individual's personal history, perceptions, feelings, perspectives and social worlds (Galletta, 2013; Hennink et al., 2010).

\section{Sample and data collection method}

In-depth interviews were used to collect data. Twenty interviews were conducted with ten male and ten female engineering academics. Five interviewees of each gender had more than ten years' research experience and the other five were in the early stages of their career and conducting their PhD studies. An equal number of male and female interviewees was sought to provide a balance in the data. Similarly, their experience was deemed an important element, as the reasons why a person is conducting research during and after their $\mathrm{PhD}$ are different, as more experienced academics will be older and more likely to have a settled family life. During the eighteenth interview, the researchers concluded that no new categories, themes, or explanations had emerged from the data; thus, the theoretical and empirical saturations were achieved (Auerbach and Silverstein, 2003; Mark, 2010) and the remaining two interviews served as confirmation of the saturation. 


\section{Data analysis}

Content analysis was used to analyse the qualitative data collected. This approach, as Krippendorff (2018) stated, enables the compression of a large number of words and text into fewer content categories based on explicit rules of coding (Bardin, 1977). The interview was the unit of analysis, following the suggestion of Graneheim and Lundman (2004), and the data was coded by paragraph and sentence, as proposed by Strauss and Corbin (1998). Also, quantitative results from Bakthavatchaalam (2018), upon which this research is built, was used to quantify academic RP and help to understand the 'why' and 'how' cultural factors influence RP.

\section{Findings and discussion}

As explained in the methodology section, a set of categories, coded a priori, were built based on a critical review of literature carried out on the impact of cultural and social factors on genders' RP. However, the categorization initially created was not intended to be closed; data analysis allowed for the establishment of emerging categories, i.e. categories that, according to their relevance to the study, have been incorporated throughout data analysis. This analysis resulted in the identification of the broad themes and categories depicted in Table 8.1.

Table 8.1: Themes and categories based on literature review

\begin{tabular}{|l|l|}
\hline \multicolumn{1}{|c|}{ Themes } & \multicolumn{1}{c|}{ Categories } \\
\hline \multirow{4}{*}{ Issues faced by women } & Sociocultural expectations \\
\hline & Family oriented issues \\
\hline & Financial issues \\
\hline & Professional and institutional factors \\
\hline & Specific policies to help female academics \\
\hline Career progression \\
\hline \multirow{5}{*}{ Resilience mechanisms } & Family support \\
\hline & Focus and concentration/dedication to work \\
\hline Male peer support \\
\hline & Changing social system \\
\hline & Increasing education for women \\
\hline & Types of research chosen by women \\
\hline
\end{tabular}


Thus, the findings and discussion section is divided into two parts. The first part discusses the barriers faced by female academics in being able to conduct research. The second part looks at the various resilience mechanisms that female academics employ to overcome these disadvantages and to be as research productive as their male peers.

\section{Issues faced by women}

One of the purposes of this study is to explore the various problems and research barriers female academics face that affect their RP. Several interesting factors emerged from the narratives and these are discussed below.

\section{Sociocultural expectations}

This category includes social and cultural norms and roles, as well as the expectations of society towards a woman. It also addresses the academics perception of this topic. The analysis revealed a range of everyday real-world difficulties that were perceived as limiting female academics. In terms of the practical difficulties, almost all the interviewed academics commented about the ability of female academics to go out for data collection and to participate in conferences, networking events, or training sessions. As an experienced female ${ }^{12}$ stated: 'Going to industries for data collection, the practicalities are less for female academics.' However, two academics commented that female academics have no barriers compared to their male peers.

Mobility (i.e. the ability to move from one city to another) was reported to be limited for female academics compared to males. An experienced male academic observed that, 'if they [male academics] get an opportunity in a different city or location, it is easier for them to move than it is for a female academic.'

The issue of female academics having a difficulty in travelling to locations to develop their research is commented on by Abramo et al. (2013), who stated that female academics' reduced mobility has a significant negative impact on their research. Mobility issues also result in a comparative lack of research networks and this is disadvantageous to female academics. This lack of physical movement and lack of interaction with men outside their family circles further

12 As indicated in the Informed consent form handed to respondents before the interview, all excerpts from narratives are anonymised. Thus, quotes are identified as 'new male academic', 'experienced male academic','new female academic' and 'experienced female academic'. 
restricts women's networking opportunities and their access to informal knowledge and the social capital that their counterparts enjoy. This hampers them not only in their research, but also promotion prospects, availing funds, pay and tenure (Paksi and Tardos, 2018).

Other practical issues that were pointed out include a female academic's general reliance on her husband or a male colleague's help in purchasing new equipment, instruments and contact with different companies for tenders and research resources. A male academic stated: 'For male academics this is easy. They would just get on their motorcycle, make a few contacts and acquire the resources and instruments quicker than a female. She will have to think a few times before being able to go and make contacts.' Another academic added that only in the last twenty years or so, that women have started to come out and be professionally active and that it is still difficult for them, but as time progresses, they will find it easier.

From a sociocultural perspective, in Indian society, there is an expectation that women play a more active role in family life; participating in the care of elders and child-rearing, among other tasks, which is seen to limit their RP (Abramo et al., 2013; Elsevier, 2017; Kyvik and Teigen, 1996). Almost half of the academics pointed out that even though society is changing, it is still male-dominated and women tend to take on a more caring role and that it will take time for women to make the transition from a caring to a competitive mind-set.

The issue with transportation plays a major role in creating a barrier for female academics. An experienced male academic stated, 'Men can travel further and they can also come home late in the evening if they want to spend more time at the laboratory or library to conduct research. On the contrary, female academics mostly depend on the college or institutional transportation, so even if they wish to spend more time at the research institution, it is very difficult for them.'

Another cultural aspect that emerged from the interviews was that woman's employment - or the income from their employment - was only seen as an additional resource to the family and not a primary income source, which usually comes from a man's employment. An experienced male academic pointed out that: 'In India, [the] male is still perceived as the breadwinner of the family. If the female is unemployed, it is ok, but it is seen as a social stigma if the man is unemployed.' 
In terms of cultural and social expectations, in line with Gupta (2014), women were seen to prefer having a lower educational attainment and salary compared to their husbands. The interviews pointed out that they still see themselves as secondary to their husbands. A good example of this is reflected by a new female academic, who commented, 'when I am with my husband and someone praises me, it feels like they say that, in a way, I am better than my husband. It makes me shy and uncomfortable. I am not sure why I feel like this, perhaps it is culturally ingrained. It is not just me, most women think the same.'

Surprisingly, three experienced male, two experienced female and one new male academic thought that there was no distinction between male and female academics in terms of cultural barriers to conducting research. They commented that, from an institutional point of view, since both genders are being paid the same, the work, quality and quantity of teaching and research would be the same and that no adjustments are required. What really surprised the authors was that these comments came from experienced academics in charge of forming and revising institutional policies.

'I do not think there are any social barriers for female academics.'

\section{- Comment from an experienced male academic}

In terms of social norms, four academics commented that the family's religious and cultural background might also be a factor that disadvantages female academics in their opportunities to conduct research.

If the family follows Islam, usually, in South India, the woman gets married at an earlier age, before taking advantage of educational and work opportunities.'

\section{- Comment from an experienced male academic}

However, Sahu et al. (2017) pointed out that females face similar barriers for HE attainment despite their religious backgrounds.

The cultural upbringing of girls was also reported to create a sense of limiting their freedom. As stated by an experienced male academic,'the main reason for women to be psychologically disadvantaged is based on how we have brought them up right from childhood.'

This was further expanded by another experienced male academic, who observed, 
Usually, girls are being cautioned a lot due to their gender. Parents say 'do not go alone, let me take you to college/school', 'are you on the bus?', 'are you safe?', etc. So, right from a young age, we have created in female[s] a sense of dependency. Suddenly, if you ask them to do it all on their own while they are conducting research, it clearly becomes very difficult for them. It is parents who have ingrained this dependency in them.

The commentator further added that this was a way of protecting their female children, a way of loving them, but, reflecting on it, they were able to see how this in a way has disadvantaged women and their research.

\section{Family-oriented issues}

Indian female academics prioritising their home, family and children more than their professional life and how it takes up considerable research time was a common theme in the interviews.

'Research requires a lot of sacrifices. It demands time. Since female academics do most of the care, child-rearing and house chores, this negatively influences their research.'

- Comment from an experienced male academic

'It is more difficult for a female academic to work on research after coming home than it is for a male.'

- Comment from an experienced female academic

'Culturally speaking, holding the family together is more important for Indian women, so whenever they feel that research constrains their family life, research becomes secondary.'

- Comment from an experienced male academic

In cultural terms, even though the Indian scenario is changing, society is still largely male-dominated. Regarding this, an experienced female academic commented, 'even if a woman is highly educated and working as an academic, men in the family point them out to their gender and use it as a kind of a controlling mechanism.' 
This has a negative impact on their identity as academics and even as women. Few of the respondents accepted that it took longer for female academics to conduct strict time-bound research with tight deadlines due to family duties, which is considerably more in comparison with males.

The data showed some of the ways marriage influences female academics and their research, such as getting accustomed to a new family environment, new family roles and responsibilities, pregnancy, child-rearing and new house chores.

'We got married when she just started her PhD and we had a child soon after. It has been three years and my wife is yet to get back to her research or academic practice. She has serious doubts if she will be able to.'

- Comment from a new male academic

The requirement for research was cited as causing additional stress for female academics in addition to that associated with their academic, teaching and family lives. It could be seen that it was clearly difficult for females to balance both spheres of their life.

Overall, the data revealed female academics have to take on more family responsibilities, which impacts on their research time. When research and academic life starts to consume family time, women were reported to face active and passive sanctions, either from their husband or from their in-laws. This again psychologically disadvantaged them. The data showed that there is still a conservative ethos in which the man is supposed to have a higher educational qualification and earning than the woman. Ego within the family was reported when the female did better than their husbands either in research, earning a higher salary, or education, etc.

'How many husbands do not have ego problems if their wife is more educated than them?'

- Comment from an experienced male academic

\section{Financial issues}

An economic model emerged from analysing the interviews. If the family is financially well off and if the husband earns a good wage, then a passive discouragement for the female to conduct research was reported. An experienced male academic said, 'my wife and I are both academics, sometimes I tell her, "what I earn is enough, there is no need for you to work and bring 
money." Thinking of it now, even though I am an academic, I feel like I stopped my wife from being an active researcher.'

The interaction between a family's economic situation and the support a female academic received was commented upon by at least six academics of both genders and experience. However, it was also seen that, if the academic was from a middle-class family or financially not so well off, then there was an expectation that the female works and contributes to the household income. In such cases, females received more support from their husbands and the family to finish their $\mathrm{PhD}$, to publish, get a promotion, have a pay raise, etc. These results are in line with the works of Sarkar et al. (2019) and Sorsa (2015), who comment on the relationship between household income and female participation in the workforce.

It was seen that the family also encouraged female academics to finish their PhD quickly as they have to pay the tuition fee every semester, adding to the family's financial commitments towards the PhD. So, this further increases the pressure for the female to finish the PhD research sooner. It is interesting to observe how economic motivation plays a role in a family's support towards the female family member's research. It also raises the question that if once the family's economic requirements are satisfied, would they still support the female family member's research endeavours?

\section{Professional and institutional factors}

The respondents reported that female academics face various barriers at the institutional level, in their work environment and the way they are perceived by their male colleagues. Seven respondents commented that they have seen instances of passive harassment towards females in institutions. This can either be from a lead researcher, a male colleague, a senior academic peer, or their research supervisors. Passive harassment included 'flirting, drooling and calling them often to talk!

'These are discomforting. Especially in India, you don't want to be direct with people, making it difficult for female academics to confront them [male academics]. There are policies available in the institutions to address active harassment, but passive ones need to be explored carefully. 
Two of the female academics commented that to avoid such circumstances, female academics prefer to have another female as their lead researcher or research supervisor. While some male academics disagreed, female academics said that it is difficult for them to be noticed and acknowledged by the management, even if they produce the same amount of research and work as their male colleagues. They felt that the institutions valued male more than female academics, thus demotivating them and negatively affecting their RP.

Almost all the academics remarked that many South Indian engineering institutions have poor research facilities. These are mostly teaching-oriented HEls, but, currently, there is a growing demand in these institutions for their academics to conduct research and publish increase institutional rankings.

'They [HEIs] have little to no laboratory or library facilities. Research is being conducted here because there is a requirement.'

\section{- Comment from an experienced male academic}

This seems to be an important factor influencing academics' choice of conducting research. How much and in what way this influences academics' motivation to conduct research should be explored carefully. Along with teaching and research, academics are also loaded with a range of administrative tasks, which is increasingly demanding of their time. Seven respondents mentioned that academics are tasked with recruiting (if needed, by knocking on potential students' doors) a certain number of students every year and also to find them jobs. This is more difficult for female academics, especially with their limited contacts and network. In line with Aiston and Jung (2015), it is not just the sociocultural and family-related factors that hinder females' research, but also the systemic and structural discriminatory practices within academia. Furthermore, studies by Ozkanlı et al. (2009) and Harley (2003), among others, point out how the HE system and structure favour masculine norms, which naturally increases female academics' difficulties.

Even within the same institution, academics' RP was noticed to differ with respect to engineering disciplines. Female academics predominantly chose to conduct research in IT, computing and electrical engineering which required less physical and field work. In these scientific departments, female academics are likely to have higher RP than in disciplines that traditionally require a more physical approach. Also, these fields do not demand expensive hardware and laboratory equipment, making it easier for the academics and the institutions to invest in 
them. These results are in line with the findings attained by Bakthavatchaalam (2018), which show that computing and IT-related departments were the most research productive, with mechanical-related departments having the lowest RP. This is also confirmed by Klasen and Pieters (2012) who concluded that the choice of subjects within engineering is influenced by gender.

\section{Specific policies to help female academics}

Most of the academics knew about some of the national schemes that encourage female academics to carry out research, which includes the flagship 'Women Scientist Scheme'13. However, at the institutional level, none of the respondents were aware of any policies that specifically prioritize and support female academics and their research.

'There is nothing that takes into consideration the barriers we face and the policies are gender-neutral.'

- Comment from a new female academic

Such a gender-neutral approach results in the institutions imposing the same teaching and research loads on male and female academics. It is important that further research and consultations are made to assess the effectiveness of such gender-neutral policies. With reference to maternity leave, interviewees commented that, even though the government allocates one year of maternity leave for female academics, the institutions do not strictly follow it, a situation that is corroborated by Gupta (2017). This is particularly so in the newly founded institutions, which cannot afford to have a temporary staff member until the female academic returns from the maternity leave. Thus, usually, female academics are requested to resign their post and if there are any suitable positions available after they finish their maternity leave, the institution would consider employing them. The following statements reflect this reality:

'There is no job security based on maternity. It's like an unwritten rule.'

- Comment from a new female academic

13 This programme was launched by the Department of Science and Technology (DST) in 2002/2003. This initiative aims to support women scientists and technologists conducting research in science and engineering. 
'Even if maternity leave is provided, it is unpaid.'

- Comment from a new female academic

This job insecurity due to pregnancy was further mentioned by a new female academic, 'if I have to quit my job because of pregnancy, then it is difficult for me to get back to the flow of conducting research. This job insecurity and the thought that I might not be able to continue research puts me off'. In addition, Gupta (2017) reported that female academics who make use of flexi-time given to them by their organization (if any), this is seen unfavourably by the hierarchy and male peers and they are unfairly perceived as not being dedicated to their work. When pressed to provide a reason for the absence of the maternity leave, flexi-time, etc., six academics commented that there has been a fall in the number of students choosing to study engineering, with many institutions having half or even lower student enrolments (AnnaUniv, 2020). This has resulted in the newly founded institutions, which predominantly depend on the students' tuition fee to run, to work in 'survival mode.' Consequently, it is hard for these institutions to provide the 'luxury' of maternity leave to their female staff.

The respondents also commented that female academics should make full use of the various government schemes that help them and that they were not doing so. This may indicate that female academics are either constrained by the status quo, or that they feel that they still do not have enough power in a maledominated society to claim or fight for their rights. The interviewees further stated that if the female academics' range of disadvantages were minimised or, ideally, eliminated and their opportunities for research increased, then their RP would be higher than that of their male counterparts. More than half of the respondents commented that there should be proper support mechanisms put in place by the HEls for female academics, especially for those with children.

\section{Career progression}

Female academics reported that they were dissatisfied with their career progression opportunities compared with male academics. Even when a female produces the same quantity of research, they felt that the management preferred to promote male academics and for them to progress quicker through the ranks.

Female academics commented that forming institutional policies that give them the same opportunities to conduct research as men, as is the current practice, 
are actually not sufficient, as they face a considerable number of other barriers compared to men.

'There is no difference in the promotion policy for male and female academics, meaning females will have to produce the same number of publications as males, but unfortunately I told you already the various difficulties they face.'

- Comment from an experienced female academic

'Women are passionate about research as well, but if the opportunities for that person to express their potential are limited, then it is difficult.'

- Comment from an experienced male academic

This suggests that female academics have to overcome more barriers to get a promotion. There were suggestions from academics that, rather than having a gender-equal promotion policy, positive discrimination for female academics would create more equality. An experienced female academic said, 'even if females are research productive and do their job well, the maximum they can progress is to be the head of the department or the dean. Most of the time, males occupy senior roles. This glass ceiling demotivates females as they know that, no matter how much and how good research they conduct, they will not be able to progress to the top management level.'

Female academics also indicated that they feel there is a considerable amount of 'underground politics' within the institution, which prioritise male academics in progressing quicker.

'A lot happens behind the scene.'

\section{- Comment from a new female academic}

These results are in line with the ones by Aguinis et al. (2018), who point out that female academics, compared to their male counterparts, would have to accrue higher social and scientific capital and resources to achieve the same level of $\mathrm{RP}$ and consequently, promotion. These sections have discussed the various barriers faced by the female academics. In order to understand the impact of these barriers on their RP, the respondents were asked to comment on their perception of the RP of genders. This is seen in the next section. 


\section{Research productivity of genders}

Three academics, two experienced female academics and one experienced male academic, pointed out that female academics' RP is the same as male academics' $\mathrm{RP}$, with one experienced female academic pointing out that females might have higher RP than men. Otherwise, the remainder of the sixteen respondents asserted that male academics produce more research papers and publications and overall have a higher RP than their female peers. Most of the respondents commented that female academics have considerably greater disadvantages compared to their male colleagues when it comes to research. Respondents who commented that female academics have equal or higher research outputs claimed that gender differences make little sense when it comes to research and that a person's RP is based solely on the individual interests and motivation.

'It is the person's commitment, nothing else matters.'

- Comment from an experienced female academic

In his research, Bakthavatchaalam (2018) quantified the RP of genders and surprisingly found no statistical difference in the RP, including the number of publications, conferences, etc., of male and female academics in South India. Furthermore, the results obtained from other cultural backgrounds such as Vuong et al., (2017), Bland et al., (2005) and Gonzalez-Brambila and Veloso (2007) also found no difference in the RP. However, other literature (Aguinis et al., 2018; Lariviere et al., 2013; Lee and Bozeman, 2005) identifies the differences in the RP of genders.

Comparing the results of the current research that shows a range of barriers facing female academics with that of the results by Bakthavatchaalam (2018), who identified that females managed to produce the same research as their male counterparts, is surprising. It clearly shows research resilience in the female academics. The next section will explore the various resilience mechanisms that female academics use and the various changes that are happening within society that help female academics conduct research and be productive. 


\section{Resilience mechanisms}

\section{Family support}

Most of the respondents mentioned the importance of family support for female academics wanting to conduct research. Two subcategories of family support emerged from the data: family support before and after marriage.

\section{Family support before marriage}

Before marriage, most respondents reported that female academics' parents predominantly took care of family responsibilities, ensuring their daughters have sufficient time to focus on their research. As a respondent said:

In Indian culture, children mostly stay with their families until marriage, with the mother doing the house chores, with the female academic helping in one or two activities.'

\section{- Comment from a new male academic}

Over the last decade, parents have started to encourage their daughters to get a master's and/or a PhD, which often means that they are ready to postpone their daughter's wedding if required. Parents also accompany their daughters to different cities, to participate in conferences and to collect data. This parental support not only helps females logistically and physically, but it also is seen to be a major psychological encouragement. As a new female academic said, 'fifteen to twenty years ago, parents would start searching for a groom when their daughter is still studying her UG, or just after, but now they encourage their daughter to study further if she desires.'

One interesting observation was that parents tend to celebrate their daughters' 'academic success' in order to increase her marriage prospects. Furthermore, it was seen that women, in general, had more time and fewer responsibilities before marriage compared to after marriage, with 'marriage' being a defining change in their life.

\section{Support after marriage}

Most of the respondents mentioned that, after marriage, the spouse's support is crucial for females to conduct research and to be successful academically. One new male academic respondent stated: 'Husbands play a major role in 
females conducting research. If there is no support from the spouse, it will be very difficult.'

Husbands were seen to support their wives in a variety of ways. Acknowledging that female academics might lack contacts, husbands use their network to assist their wives. They assist them in data collection, travel with them to different places for participation in conferences and support them by sharing household chores.

Along with the husband's support, support from the husband's family, such as the in-laws, was also reported to be important. A new male academic said, 'without the support of in-laws in a joint family, it is very difficult in the Indian scenario for a female to be able to balance both personal and professional life.'

However, on the positive side, a new female academic said, 'a joint family is advantageous because the female will have some reassurance that her children would be looked after by the family members while she is conducting research, whereas in a nuclear family, she will have to [do] most of the work.'

Some respondents mentioned that there has been a change in the family structure, from joint to nuclear families and commented that this new family structure has both advantages and disadvantages for female academics. It is advantageous, as, with fewer family members to attend to, female academics can dedicate more time and effort to research. One experienced male academic said, 'being in a nuclear family shields the couple from the various 'gossips' and the societal and cultural expectations that would be placed on them if they were living in a joint family, thus increasing females' freedom to conduct research.'

Gupta (2014) comments that with the decreasing number of joint families, young couples can have more egalitarian attitudes with women finding it easier to come out of their homes and be employed and be more independent. Such social changes would enhance women's opportunities to conduct research.

Respondents also mentioned that some husbands shared aspects of their wives' research, including data collection, analysis and writing up reports. As one new male academic stated: 'If the husband and wife are working in the same (academic/research) field, then sometimes it is indistinguishable whose research that is.'

It was observed that even though husbands understood their wives' academic ambitions and supported them in any way they could, they still expected 
them to prioritize the family needs. As one young female academic said, 'if her professional and research life starts eating into the family life, then the support the family offers her starts to erode.'

Interestingly, the link between the overall financial condition of the family and support for the female's research was revealed by the data. It was reported that the husband's support is lower in a financially affluent family compared to the situation when there is a financial requirement for the wife to contribute to the household income. Even though there is an increasing support before and after marriage, there are arguments (Bakthavatchaalam, 2018), that the support before marriage is mostly to increase their marriage prospects to a well-off educated person and that the support after marriage is to increase the financial status of the family. Even if this is so, the output of this increasing support has positively influenced female academics' RP. Overall, these societal changes have positively influenced female academics in their RP and as a spill over, their confidence in research.

\section{Focus and concentration/dedication to work}

Another resilience mechanism that emerged from data was female academics' ability to focus and work without getting distracted compared to their male counterparts. Irrespective of the gender and experience, this was reported at least ten times by the respondents. An experienced male academic said that, 'women procrastinate less, at least in their research work, are more organized and plan ahead, giving them an edge.'

The focus of female academics and the quality of their research were mentioned by an experienced female, who said, 'in terms of the duration of conducting a $\mathrm{PhD}$, even if a male and a female academic start their research at the same time, females finish it quicker and also with higher quality.'

In addition to the focus of females towards their research, males' easy-going nature was pointed as a contributing factor. For instance, a new male academic said that, 'men get easily distracted and make jolly, just keep postponing their research on a regular basis, compared with women.' Another new male academic said, 'when a male academic sits to do research, he thinks, "let me go have a cup of tea or let me call my friend, etc.", whereas a female tries to finish as much as she can without getting distracted. This might work to their advantage.'

Six academics, two experienced males and females and one new male and female, commented that female academics were very good in data analysis 
and writing up, compared with their male peers. Male academics were reported to be good in networking and collecting data, especially if it is physical or field work. An experienced male academic said, 'if you give them [females] the data, they can sit and finish it, even if it takes a long time, unlike men. To share a personal incident, my wife, who is also an academic, spent almost four hours last night working through her data, whereas if it were me, after 10 pm I would say "well, let us see tomorrow" [laughs].

Looking at these findings, the authors do question if there has actually been any change in the traditional gender roles in the target society. Comparing this situation to prehistoric times, when men went hunting and women predominantly stayed at home and cooked, the current situation looks analogous, in that male academics go hunting for data and do the physical work, whereas female academics analyse and write up the research. It could be interesting to explore the changing gender roles, not only within academia but also at a societal level. Further research will have to be carried out to look into male and female academics' self-efficacy and focus, as it is unclear what factors enable female academics to focus better than their male counterparts and the reasons why male academics are easily distracted.

What really surprised the authors was that even though half of the respondents commented that women are more focused and are good with data analysis and writing up, they also commented that despite the above skills, women still have a lower RP than men. This is contradictory.

\section{Male peer support}

Most female respondents commented that other male academics, peers help them in conducting research, for instance, to travel to buy some equipment, to visit a laboratory, etc. An experienced male academic said: 'Male academics are aware that females have certain disadvantages, so they try to help them in their research and some administrative tasks.'

In addition, a new female academic stated: 'It is not possible for me or other female academics to do all the work by ourselves, so usually I offer ideas to my students and colleagues and ask for help. I cannot take the full credit for the work, but it is a mutually beneficial work for us all.'

This academic further indicated that not only male peers of the same rank, but also senior male academics, assist them. However, at least two academics mentioned that male academics tend to support their female peers only after 
they had achieved their own targets and that helping female colleagues might not be their priority. Overall, the results show that female academics' RP was positively influenced by their male colleagues' support. At the same time, it further deepens a sense of dependency on their male counterparts. One of the interesting results that emerged from the data was the increasing trend of academics to get married within academia, as remarked by at least four respondents. This perhaps gives both partners a better understanding of what the other person is going through and the various avenues in which they can produce synergies together to benefit each other. As one of the experienced male academics said, 'don't be surprised if you go to any institution and you find at least three or four couples.'

There are also instances in which the husband adds his wife's name as gratis in his papers, especially if they are both working in the same domain. As an experienced male academic stated: If my wife is not actively participating in any of the research that I conduct, I have her name as a co-author, just for her career growth:

Overall, the increasing understanding and assistance provided by male colleagues has a positive influence on a female's RP.

\section{A changing social system}

The data revealed a variety of changes that are happening in the social and cultural system in South India that enable and support female academics in their RP. The changing social system was divided into the following subcategories: (1) Changing gender roles; (2) Increase in the age of marriage; (3) Increase in the confidence of women; and (4) An increase in education for women. The changes are not just within academia; rather, these are wider social changes, whose impact overflows into academia.

\section{Increasing education for women}

Seven respondents reported that parents wanted their female children to be highly educated and employed before getting married. This shift in the parents' perception of their daughters' role in society enables women to build resilience. It also enables them to be financially independent of their husbands and their husbands' family. Parents see education and employment as 'insurance' for their daughters in case something goes wrong with the marriage. Regarding the increase in female education, a new male academic said: 
Twenty years ago, if you look at the wedding invitation cards, mostly, they would only show the groom's educational attainment and workplace. The bride's won't be as she might not have a degree or employment. However, in the current invitations, you have the educational attainment and workplace of both the bride and the groom. This not only shows an increase in women's education, but also how proud their families are to exhibit their daughter, daughterin-law's education and employment. This shows a huge change.

Looking at this particular development, the authors are encouraged to expect this upward trend to continue. When more women are highly educated and enter the professional world, they not only gain more exposure and confidence, but also create a positive impact on society, serve as role models and inspire young girls and other women. Furthermore, comparing the findings of this study with the results of a study on female engineers in India from fifteen years ago (Patel and Parmentier, 2005) that concluded that increasing education and technological changes did not equate to a redefining of the gender roles, we believe that this redefinition is now well underway.

An experienced female academic said, 'parents see their daughters being employed as a positive social status, whereas, before, this was widely not the case. This increased education and opportunity give[s] them confidence both personally and professionally.'Two more academics indicated that, even though there may be no economic requirement for the daughter to work, the families still support and encourage their daughter to work before and even after marriage, depicting a changing mind-set.

On the whole, results show how society has increasingly started to value females and their education. All these shifts are seen to be positively influencing female academics' resilience. As a new male academic stated: 'Fifteen years ago, parents educated their male child [more] because there was an inherent expectation that their male child would take care of them during old age, but now they think that their daughters are the ones who will take care of them. So, they are more interested in making sure that their daughter is equally educated as their male child or even better educated.

\section{Changing gender roles}

The data suggested that the strict gender roles that were prevalent a couple of decades ago in India are now getting more blurred. One of the major reasons for 
this was reported to be an increasing professional understanding of the married couple in terms of each other's employment requirements and how it affects their family life. Earlier, mostly the husbands were involved in paid employment and females predominantly did the household chores, whereas today, when the wives also work, the husbands usually try to share a few household chores. The change in this regard can be explicitly seen from the statement of an experienced male academic, who said, 'my mother will be unhappy if she sees me doing house chores. In her generation, it was predominantly female's work, but now, we [him and his wife] take it as a shared responsibility. This sharing in a way might enhance female academics' RP.'

Historically, the in-laws have had a huge influence on the decisions of the family, including their daughter in law's employment or the restriction of it. Yet, the data show that there has been a change in the perception of the in-laws regarding the gender roles of their son and his wife. A new female academic said, 'years ago, daughters-in-law working was not seen in a positive light. However, now this has changed considerably. To say that their daughter-in-law is working, for instance, as an academic is seen as a positive status symbol and they are very happy to showcase this.'

This change in perception is not just reflective of their daughter-in-law's employment, but also an acknowledgement of the changing gender roles within the family. In addition, it is about the more flexible nature of gender roles and its celebration or, at least, its acceptance. The results suggest that there is a shift in the societal attitude regarding gender norms. For instance, most of the respondents commented that, unlike twenty years ago, when gender roles were comparatively strict, currently there is an ease of it within the family. Men are happy to share house chores with their wives and they are taking on considerably more family responsibilities. The social and cultural transformation that is taking place was either seen by some as progressive but by others as culturally detrimental. However, everyone acknowledged the changing social system and the reduction of the once strict gender roles.

\section{Increase in the age of marriage}

In Indian society, the age for marriage is, traditionally, different for men and women. It is well accepted that a man gets married in his late twenties, whereas, for women, this age is considered too late. This may still be a hindrance for women who wish to progress academically. As an experienced male academic said, 'if a female gets married just after her master's, she would be around 23, 24, 
which is seen as the normal age for getting married. But if she chooses to do her PhD just after the master's, by the time when she finishes it and publishes a couple of papers, she will be around 29 years old and that is considered to be old!

However, this is starting to change and the families are now happy and willing to postpone their daughter's marriage in favour of her education and employment. Four of the interviewed academics said that there is a steady increase in the age of females getting married in South India, at least for those who are working in HE. This has increased the opportunities for women to study and work before marriage. One experienced male academic acknowledged these changes and the resulting advantages for female academics by stating, 'the parents advocate that, even if it takes a couple of years for their daughters to finish their master's or their research work on their PhD, then let it be so and after that, they can get married. This is an important social change that has happened in the last decade or so.'

However, a couple of academics, experienced male and female, were quite conservative and sceptical about women getting married in their late twenties, whereas for men, it was still felt to be a reasonable age for marriage. This suggests that even now, few of the older academics are still under the influence of the traditional way of envisaging the gender roles. Yet, there is a definite change. This shift in the sociocultural system is bringing benefits for women in their academic progression and RP, as they are now increasingly having the opportunity to invest in their education before marriage.

\section{Increase in the confidence of women}

The data pointed out that one of the reasons for female academics' research resilience is the increased confidence of women, due to changes in the sociocultural system in the last twenty to thirty years. However, at least five of the academics pointed out that even though there is an increase in women's empowerment, there are still boundaries.

'The range of freedom has increased considerably, but they [women] still operate within the current social norms.'

- Comment from a new male academic

An experienced female academic said, 'ten years ago, I would be expected to be at home at around six pm or so, but now I can come home at around 8 or 9 
$\mathrm{pm}$. There has been an increase in freedom. However, the expectation is that I will be home at that time and not be working or conducting research until 10 or $11 \mathrm{pm}$. Our society has not probably evolved to that level.'

The data also pointed out that, since women are, today, better educated, they are more demanding of their rights compared to a decade ago. A new female academic said, 'well, I am well educated, I am earning money, and if my opinions are not respected, then I am not very happy and I will express my dissatisfaction. This was not the case for the previous generation.

The increase in women's confidence was explicitly visible when a new female academic stated: 'Twenty years ago, if a lady went to talk with a male colleague, people would look at it strangely, but now it is considered a common thing. Earlier, my husband would not really like me going and talking with other male academics, but not nowadays, especially if it is for professional, academic purposes.'

This has opened up new avenues for female academics to discuss their research with male peers and to expand their network. One experienced male academic pointed out the increase in female academics' confidence and the social view of it with the following comment, 'they [female academics] are more confident now. Just look at the movies that come out, a lot of them speak of women empowerment.'

Within STEM, it seems that female academics are learning to deal with adversity, in sociocultural, institutional and scientific terms. The work of Richman et al. (2011) stresses that women are becoming more successful and are striving effectively in STEM-related disciplines, despite still being a minority. Whether these changes will be sufficient to bring about SDG 5 in HE research is questionable.

\section{Type of research chosen by female academics}

Gender differences were noticed in the type of research female academics chose to conduct. Five of the respondents mentioned that female academics choose disciplines that require less travel and are more institutional-based. The data showed that females chose to conduct research in areas that required less fieldwork compared with men. This reduced some of the disadvantages seen in the previous section. A new female academic commented, 'if they [female] choose research which does not demand a lot of fieldwork, then it is easy. 
For example, a topic that is more computer-based and also being closer to home and being able to work from home.'

Furthermore, to overcome some of the mobility barriers faced by female academics, it was reported that they seek the assistance of their students and fellow male peers, either for long-distance travel or to a particular place where they might not feel comfortable or safe. An experienced female academic stated that this approach was a 'smart' way of overcoming the travel barrier.

Similarly, an experienced male academic said, 'if the research is about bringing out a new product or a process or implementation, then it is difficult for them [female academics] compared with males.'

In summary, the choice of the type of research that female academics conduct is seen to be conditioned by the hurdles they have to face in a still traditional, yet changing society. The next section brings together the issues faced and the approaches female academics used to overcome barriers and restrictions.

\section{Relationship between the barriers and the resilience mechanisms}

Even though the results show decreasing social and cultural impediments for females, they still operate in a patriarchal society in which females face considerable control (Batra and Reio, 2016; Bhattacharyya, 2014). Data showed evidence of family members using gender as a controlling mechanism, even if the female is highly educated. Such patriarchal thoughts have had a spill-over effect in organizational policies as well.

Shukla (2015) found in her work that even though the younger generation were less traditional and more supportive of women's employment, men still expected women to shoulder child-care and household responsibilities, which they considered women's primary role and not their professional and research development. Conducting research demands a considerable amount of personal time, but sociocultural expectations increase the chores females have to perform after coming home, thus further hampering their work-life balance and their RP.

Shukla (2015) also points out that gender roles in India are undergoing a considerable transformation, albeit slowly. This includes an increased professional understanding; husbands getting more involved with domestic chores; helping 
their wives with their research by using their networks; and also assisting with data collection, thereby allowing their spouses to focus on their research more intensively. In the institutional environment, male colleagues who are ready and willing to help their female colleagues with their research also help the females' RP potential. It should be noted that the word 'help' - not 'collaborate, or share' - is used profusely by both male and female respondents when referring to the professional relationship between the genders. The same word, help, was used in a family scenario as well. By giving or not giving help, it could be argued that men, either a family member or a male peer, still have an important influence on the potential success, or lack of success of female colleagues and spouses.

Mobility constraints affecting female academics was cited as one issue that limited their opportunity to conduct research and further their professional development. One solution to this could be online-networking, especially with increased use of the Internet, which, in theory, should enhance female academics' networking opportunities. Exploring this idea, Paige Miller and Shrum (2012) state that female academics' networks still tend to be localized and not broad. By embracing the opportunities online networking offers, female academics could offset some of the disadvantages, as commented by three of the female respondents, who mentioned their growing online network and the research openings it has provided them.

Looking at the respondents' narratives, it can be commented that, given that female academics have considerable travel constraints when collecting data, they have little choice but to become experts in writing literature reviews, analysing data, etc. Furthermore, female academics have to make greater efforts to start and be resilient to continue their academic career. This might be one of the reasons for them to be very focused and dedicated, as they have little room to make mistakes. Institutional closures during COVID-19 resulted in a drastic increase of online education and research in academia, making it common place. This situation has increased not only online teaching and learning, but also online research and networking between academics. It remains to be seen how this has influenced academics' RP and if there are any gender differences in $\mathrm{RP}$ during the lockdown.

However, from the interviews, it was noticed that currently there is increasing support from female academics' families both before and after marriage, which enables them to overcome the mobility barrier to a certain extent. While having a male family member willing to accompany them will potentially provide them with new research and networking opportunities, it still raises the question of 
overdependence on the other gender. This needs further consideration in the promotion of SDG5, gender equality.

Mitra and Pooja (2007) point out the importance of a change in the social and cultural norms, along with female education, to create gender equality. The vicissitudes in the last thirteen years after their article was published reflect the required changes in people's attitude starting to take place, which is encouraging. Rather than considering that the increase in females' RP as largely due to the male family member's help, these findings represent a wider change. They embody a changing society, its norms and a changing cultural perspective. They are seen as a reflection that society as a whole has started to acknowledge the potential of female academics and women in general, increasing their opportunities to succeed. It should be acknowledged that there are abundant problems surrounding this transition, but what really interests the researchers is to see this transition happening, slowly but steadily. This is an encouraging step towards achieving gender equality. Overall, these societal changes have positively influenced female academics in their RP and especially their research resilience.

Currently, there is an increasing awareness among parents about the importance and advantages of females pursuing $\mathrm{HE}$, including the financial and social independence it offers their daughters. The families postponing their daughters' wedding for them to pursue research programmes such as a PhD stands out as a prime example. For instance, Das and Das (2018) comment on how increasing educational opportunities has impacted positively on a woman's age of marriage and their consequent social wellbeing. These are important social changes positively impacting female employment, research and vice versa. As UNESCO research (2017) stated, these women in turn serve as role models for younger women to pursue their educational and research goals.

Even after marriage, there is increasing support from husbands to their wives to pursue research and increasingly, also from their in-laws. Even though it was reported that this support is mostly for economic reasons, i.e. to increase the family's income, this trend has enabled greater research opportunities for wives, with a related increase in their confidence, employment opportunities and financial independence. Data shows academic managers and those at the policymaking levels in HEls are happy with the promotion of genderneutral policies for research and promotion opportunities. Although this seems a positive development, it actually disadvantages female academics as they have to overcome comparatively more barriers than men to have the same RP. 
The institutional practices, though said to be gender-neutral, in reality, these do not result in gender equality. Employment practices, such as females losing their post due to pregnancy and child-rearing demands, need to change, as they create job insecurity and result in women leaving research and academia. Regarding promotion, even with the 'gender-neutral' policies the institutions propose, females presume there is a 'glass ceiling' and that it is easier for their male counterparts to achieve professional advancement. Institutional policies making promotion and pay rise decisions more open could address this issue. It is essential for institutions to break down the barriers women face, which are usually accepted as the norm (Batra and Reio, 2016). This can be done by first acknowledging the existence of the sociocultural barriers female academics face, exploring the barriers and finally, forming policies and practices to eliminate them. To promote active research collaboration between the genders, it is essential for the institutions to form and actively follow the practices related to the 'passive harassment' that was reported. This is especially important in engineering and other STEM related institutions where females are in the minority.

Focusing on engineering education and research, traditional engineering disciplines such as civil, mechanical and manufacturing engineering are still dominated by men. Whereas the emergence of disciplines such as electronic and communications engineering, computing and $\mathrm{ICT}$, which require less physical work, has motivated more females in these disciplines. For instance, Gupta (2014) stated that in India, a'woman-friendly' image of ICT and computing engineering fields is developing. Moreover, the current increased opportunities to study engineering and job prospects in this field have encouraged greater female participation. Even in the disciplines that demand a lot of fieldwork, travel and laboratory equipment, such as civil and mechanical engineering, currently there is an impetus towards inter-disciplinary research, programming, design, simulation and online testing etc., which can be done with a computer and from home. This could, in the future, make these scientific fields more femalefriendly and increase female participation and research in these areas. This is an encouraging possibility. These changes could factor in to fix the 'leaky pipeline' as highlighted by Huyer (2015), where even though the enrolment in science and engineering is high for females in UG, when it comes to PhD level and choosing a research career, there is a huge drop in female numbers compared to men.

It is essential that institutions promote the evolution of engineering as a femalefriendly area for study and research and form policies that support this transition, 
both for aspiring female students and female academics. The results from this research allowed the development of a model that brings together the essence of the various factors identified (Figure 8.1). The model depicts a number of hurdles Indian female academics in STEM have to overcome, namely through a set of resilience mechanisms that they have developed and which are also the results of the changing Indian sociocultural system.

Figure 8.1: Model of Indian female academics' research productivity in STEM

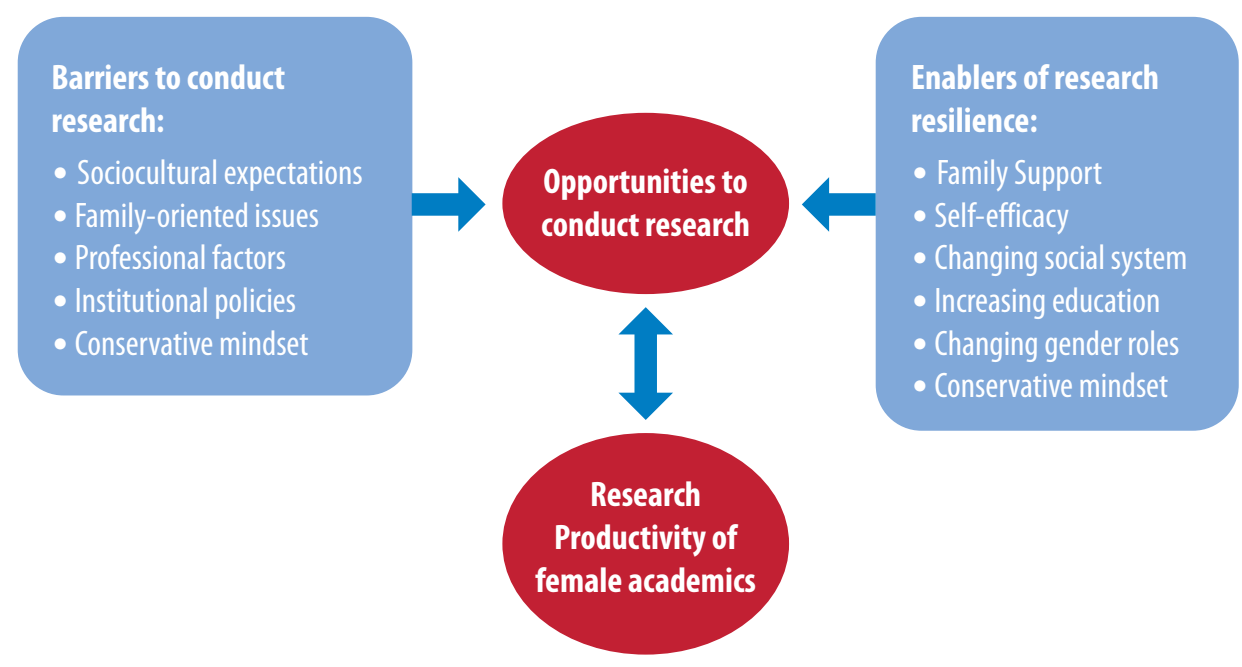

Source: developed by authors

\section{Conclusion and recommendations}

Academics are the heart and soul around which research and HEls are built (Enders, 2007). Unfortunately, many female academics are held back by a range of factors, including social norms and expectations derived from gender discrimination and bias. There is a considerable body of evidence that suggests female academics inspire more female students to enter STEM education (UNESCO, 2017) and currently there are an increasing number of female engineering academics who may positively influence more females to choose an engineering course and successfully forge a career in this discipline. Overall, this paper shows a considerable resolve in female academics in wanting to match or even better their male counterparts in research, despite the hurdles they face. The research is based on a sample of twenty academics, which the 
authors believe should be increased in future research to better understand the mechanisms used to achieve this resolve.

Some of the contributions of this paper are that it has identified the various issues faced by female academics and that, despite these disadvantages, they manage to produce the same research as their male counterparts. Research has also identified some of the mechanisms they use to overcome their disadvantages and importantly, how the evolving cultural and social factors aid in the process. The authors acknowledge that this research has just scratched the surface and that further investigation could unearth a range of hidden factors.

The studies suggest that when HEls, policymakers and governing-bodies form their research policies, they should consider gender differences and cultural factors. Proper provisions should be put in place to support female academics in their research activities. Also, interventions through targeted public policies could potentially reduce the influence of cultural factors impacting on females' RP. This would seek to bring about and foster equitable conditions and opportunities for male and female academics and would empower them to conduct quality research. The identified mechanisms which female academics appear to employ can be more widely adopted, not only in Indian academia but as a reference in the wider labour market in other developing countries and similar cultural systems.

Such policies should enhance gender equity (SDG5) in the workplace, especially in terms of research and also reduce inequality in research opportunities (SDG10). This approach would have a huge and favourable impact on the quality of the research produced and ultimately, influence the quality of wider education (SDG4). The lessons from this research could be applied to institutions specializing in disciplines other than engineering and also, with an understanding of local data, to institutions in other parts of the country. The results of this research can be used as a basis for further investigation; for institutions to develop their research policies; and to help their academics conduct and produce high-quality research and publications.

\section{Limitations of the research and future work}

Just like any other qualitative study, generalizability is a major limitation of this study. This research was conducted in Coimbatore's (a city in the South Indian state of Tamil Nadu) engineering institutions, which might reflect the situation 
in South India, but generalizing it to the whole country or Asia should be done carefully, as the socio-economic and cultural milieu are different. A nationwide or a South-East Asia wide study could be conducted in the future that could compare the different geographic regions and female academics' RP and their resilience. To make inferences from the small sample of engineering academics, to academics in disciplines such as humanities, science, medicine, etc., might potentially be limited and must be done with caution. One commonality between the target academics and academics from different disciplines would be that they would have all largely come through the same education system and will currently be operating in a similar cultural environment.

The lack of empirical research in this subject area in India limits the potential to compare the results with that of other studies. As interest in this field increases, there will be more opportunities to further investigate this. In this research, the RP measured is based only on the number of different publications and future studies might consider both the quantity and quality of publications, including the citation index, the impact factor, etc. A longitudinal study could be conducted to assess how, over time, the changing academic environment and the sociocultural system influence the opportunities for female academics to conduct research and consequently, their RP.

\section{References}

Abramo, G. and D'Angelo, C. A. 2014. How Do You Define and Measure Research Productivity?. Scientometrics. Vol. 101, No. 2. pp. 1129-1144.

Abramo, G., D'Angelo, C. A. and Murgia, G. 2013. Gender Differences in Research Collaboration. Journal of Informetrics. Vol. 7, No. 4. pp. 811-822.

Acker, J. 2006. Inequality regimes: Gender, Class, and Race in Organizations. Gender \& society. Vol. 20, No. 4. pp. 441-464.

Adams, J. D. and Clemmons, J. R. 2009. The Growing Allocative Inefficiency of the US Higher Education Sector. Science and engineering careers in the United States: An analysis of markets and employment. University of Chicago Press, pp. 349-382. 
Aguinis, H., Ji, Y. H. and Joo, H. 2018. Gender Productivity Gap Among Star Performers in STEM and Other Scientific Fields. Journal of Applied Psychology. Vol. 103 (12), No.12. pp 1283-1306.

AISHE, Development, M.o.H.R. 2019. All India Survey on Higher Education 2018-19. New Delhi, Government of India.

Aiston, S. J. and Jung, J. 2015. Women Academics and Research Productivity: An International Comparison, Gender and Education. Vol. 27, No. 3. pp. 205-220.

Aksnes, D. W. 2012. Review of Literature on Scientists' Research Productivity. IVAs projekt Agenda för forskning. pp. 2-12. Available: IVA.

Aksnes, D. W., Rorstad, K., Piro, F. and Sivertsen, G. 2011. Are Female Researchers Less Cited? A Large-Scale Study of Norwegian Scientists. Journal of the Association for Information Science and Technology. Vol. 62, No. 4. pp. 628-636.

Altbach, P. 2015. What Counts for Academic Productivity in Research Universities?. International Higher Education. Vol. 79. pp. 6-7.

Amaral, A., Neave, G., Musselin, C. and Maassen, P. 2009. European integration and the Governance of Higher Education and Research. Dordrecht, Springer.

AnnaUniv. 2020. Database of Affiliated Colleges in Tamil Nadu. Chennai, Anna University. https://www.annauniv.edu/cai/Regioncoimbatore.php.

Arimoto, A., Teichler, U. and Cummings, W. 2013. The Changing Academic Profession: Major Findings of A Comparative Survey. Dordrecht, Springer.

Astegiano, J., Sebastián-González, E. and Castanho, C. 2019. Unravelling the Gender Productivity Gap In Science: A Meta-Analytical Review. Royal Society Open Science. Vol. 6, No. 6. pp. 1-12.

Auerbach, C. and Silverstein, L. B. 2003. Qualitative Data: An Introduction to Coding and Analysis. NY, NYU press.

Bakthavatchaalam, V. P. 2018. Motivation to Conduct Research in a Rapidly Evolving Academic Environment: Study Of Coimbatore's Engineering Institutions. PhD, University of Plymouth, Plymouth, UK.

Bakthavatchaalam, V. P., Miles, M., Sa, M. J., Machado-Taylor, M. d. L. and Gingele, J. 2019. Gender and Research Productivity of Academics in South India's HEls. 2nd International Conference on Gender Research. Rome, ACPI, pp. 685692.

Bardin, L. 1977. Análise de conteúdo [Content analysis]. Lisbon, Edições 70.

Batra, R. and Reio, T. G. 2016. Gender Inequality Issues in India. Advances in Developing Human Resources. Vol. 18, No. 1. pp. 88-101. 
Bhattacharyya, R. 2014. Understanding the Spatialities of Sexual Assault against Indian Women in India. Journal Gender, Place \& Culture, A Journal of Feminist Geography. Vol. 22, No. 9. pp. 1340-1356.

Bland, C. J., Center, B. A., Finstad, D. A., Risbey, K. R. and Staples, J. G. 2005. A Theoretical, Practical, Predictive Model of Faculty and Department Research Productivity. Academic Medicine. Vol. 80, No. 3. pp. 225-237.

Bosanquet, A. 2017. Academic, Woman, Mother: Negotiating Multiple Subjectivities During Early Career. Gender and Education. London, Springer, pp. 73-91.

Callaghan, C. 2015. Intrinsic Antecedents of Academic Research Productivity of A Large South African University. Southern African Business Review. Vol. 19, No. 1. pp. 170-193.

Carayol, N. and Matt, M. 2006. Individual and Collective Determinants of Academic Scientists' Productivity. Information Economics and Policy. Vol, 18, No. 1. pp. $55-72$.

Das, K. and Das, M. 2018. Women And Wedlock: A Study on Female Marital Status among the Hindus, Muslims and Christians of Assam, India. Space and Culture. Vol. 6, No. 1. pp. 107-119.

Denzin, N. K. and Lincoln, Y. S. 2011. The Sage Handbook of Qualitative Research. California, Sage.

Deshpande, A. 2019. Choice, Constraints and Cultural Norms: Understanding Factors Underlying Women's Labour Force Participation in India. UNU-WIDER Seminar Series. Helsinki, Finland, UNU-WIDER.

Diogo, S. 2015. Same Challenges, Different Processes: Perceptions on Governance Changes in Portuguese and Finnish Higher Education. European Journal of Higher Education. Vol. 5, No. 2, pp. 211-225.

Ebadi, A. and Schiffauerova, A. 2016. How to Boost Scientific Production? A Statistical Analysis of Research Funding and Other Influencing Factors. Scientometrics. Vol. 106, No. 3. pp. 1093-1116.

Enders, J. 2007. International Handbook of Higher Education. The Academic Profession. Dordrecht, Springer, pp. 5-21.

Fox, M. F. 2005. Gender, Family Characteristics, and Publication Productivity among Scientists. Social Studies of Science. Vol. 35, No. 1. pp. 131-150.

Frolich, N. and Caspersen, J. 2017. How does Policy Change Universities? Outlook on the Global Research Agenda. State of Higher Education - 2015-16. Paris, OECD, pp. 127-132.

Galletta, A. 2013. Mastering the Semi-Structured Interview and Beyond: From Research Design to Analysis and Publication. NY, NYU press. 
Gonzalez-Brambila, C. and Veloso, F. M. 2007. The Determinants of Research Output and Impact: A Study of Mexican Researchers. Research Policy. Vol. 36, No. 7. pp. 1035-1051.

Graneheim, U. H. and Lundman, B. 2004. Qualitative Content analysis in Nursing Research: Concepts, Procedures and Measures to Achieve Trustworthiness. Nurse education today. Vol. 24, No. 2. pp. 105-112.

Gupta, N. 2014. Rethinking the Relationship between Gender and Technology: A Study of the Indian Example. Work, Employment and Society. Vol. 21, No. 4. pp. 661-672.

Gupta, N. 2017. Gender Inequality in the Work Environment: A Study of Private Research Organizations in India. Equality, Diversity and Inclusion: An International Journal. Vol. 36, No. 3. pp. 255-276.

Harley, S. 2003. Research Selectivity and Female Academics in UK Universities: From Gentleman's Club and Barrack Yard to Smart Macho?. Gender and Education. Vol. 15, No. 4. pp. 377-392.

Hennink, M., Hutter, I. and Bailey, A. 2010. Qualitative Research Methods. London: Sage.

Holman, L., Stuart-Fox, D. and Hauser, C. 2018. The Gender Gap in Science: How Long until Women are Equally Represented?. PLOS Biology. Vol. 16, No. 4.

Horodnic, I. A. and Zait, A. 2015. Motivation and Research Productivity in a University System Undergoing Transition. Research Evaluation. Vol. 24, No. 3. pp. 282292.

Huang, F. 2019. Field of Higher Education Research. Encyclopedia of International Higher Education Systems and Institutions. Dordrech, Springer, pp. 1-7.

Hunter, L. A. and Leahey, E. 2010. Parenting and Research Productivity: New Evidence and Methods. Social Studies of Science. Vol. 40, No. 3. pp. 433-451.

Huyer, S. 2015. Is the Gender Gap Narrowing in Science and Engineering. UNESCO science report: Towards 2030. Paris, UNESCO, pp. 85.

IMF. 2015. India: Selected Issues Paper. Washington, International Monetary Fund.

Katoch, O. R. 2012. Job Satisfaction among College Teachers: A Study on Government Colleges in Jammu ( $\&$ \&). Asian Journal of Research in Social Science \& Humanities. Vol. 2, No. 4. pp. 164-180.

Klasen, S. and Pieters, J. 2012. Push or Pull? Drivers of Female Labor Force Participation during India's Economic Boom. IZA Discussion Paper No. 6395. pp. 1-36.

Knobloch-Westerwick, S., Glynn, C. J. and Huge, M. 2013. The Matilda Effect in Science Communication: An Experiment on Gender Bias in Publication Quality Perceptions and Collaboration Interest. Science Communication. Vol. 35, No. 5. pp. 603-625. 
Krippendorff, K. 2018. Content Analysis: An Introduction to Its Methodology. 4th ed. Thousand Oaks, CA, Sage.

Kyvik, S. and Teigen, M. 1996. Child Care, Research Collaboration, and Gender Differences in Scientific Productivity. Science, Technology, \& Human Values. Vol. 21, No. 1. pp. 54-71.

Lariviere, V., Ni, C., Gingras, Y., Cronin, B. and Sugimoto, C. 2013. Bibliometrics: Global Gender Disparities in Science. Nature. pp. 211-213.

Lee, S. and Bozeman, B. 2005. The Impact of Research Collaboration on Scientific Productivity. Vol. 35, No. 5. pp. 673-702.

Machado-Taylor, M. d. L., Soares, V. M. and Teichler, U. 2017. Challenges and Options: The Academic Profession in Europe. Swiss, Springer.

Mark, M. 2010. Sample Size and Saturation in PhD Studies Using Qualitative Interviews. Qualitative Social Research. Vol. 11, No. 3.

Merriam, S. and Tisdell, E. 2009. Qualitative Research: A Guide to Design and Implementation. San Francisco, John Wiley \& Sons.

Mitra, A. and Pooja, S. 2007. Human Capital Attainment and Gender Empowerment: The Kerala Paradox. Social Science Quarterly. Vol. 88, No. 5. pp. 1227-1242.

Nygaard, L. P. 2015. Publishing and Perishing: An Academic Literacies Framework for Investigating Research Productivity. Studies in Higher Education, Vol.42, No.3. pp. 519-532.

Oshagbemi, T. 2000. How Satisfied are Academics with their Primary Tasks of Teaching, Research and Administration and Management?. International Journal of Sustainability in Higher Education. Vol. 1, No. 2. pp. 124-136.

Ozkanlı, O., Machado-Taylor, M.d.L., White, K., O'Connor, P., Riordan, S. and Neale, J. 2009. Gender and Management in HEls: Changing Organisational and Management Structures. Tertiary Education and Management. Vol. 15, No. 3. pp. $241-257$.

Paige Miller, B. and Shrum, W. 2012. Isolated in A Technologically Connected World?: Changes in the Core Professional Ties of Female Researchers in Ghana, Kenya, and Kerala, India. The Sociological Quarterly. Vol. 53, No. 2. pp. 143-165.

Paksi, V. and Tardos, K. 2018. Networks in Science: Women's Research Collaborations and the Old Boys' club. pp. 39-48.

Patel, R. and Parmentier, M. J. C. 2005. The Persistence of Traditional Gender Roles in the Information Technology Sector: A Study of Female Engineers in India. Information Technologies \& International Development. Vol. 2, No. 3. pp. 29-46. 
Prpic, K. 2002. Gender and Productivity Differentials in science. Scientometrics. Vol. 55, No. 1. pp. 27-58.

Ramesh Babu, A. and Singh, Y. 1998. Determinants of Research Productivity. Scientometrics. Vol. 43, No. 3. pp. 309-329.

Rani, G. 2010. Changing Landscape of Higher Education in India: The Case of Engineering Education in Tamil Nadu. National University of Educational Planning and Administration. pp. 1-59.

Richards, G. P. 2006. Managing an Academic Career in Science: What Gender Differences Exist and Why? University of Maryland.

Richman, L. S., Vandellen, M. and Wood, W. 2011. How Women Cope: Being a Numerical Minority in a Male-dominated Profession. Journal of Social Issues. Vol. 67, No. 3. pp. 492-509.

Ropers-Huilman, R. 2002. Aren't You Satisfied Yet? Women Faculty Members' Interpretations of their Academic Work. New Directions for Institutional Research. pp. 21-32.

Rorstad, K. and Aksnes, D. W. 2015. Publication Rate Expressed by Age, Gender and Academic Position-A Large-scale Analysis of Norwegian Academic Staff. Journal of Informetrics. Vol. 9, No. 2. pp. 317-333.

Sahu, B., Jeffery, P. and Nakkeeran. 2017. Barriers to Higher Education: Commonalities and Contrasts in the Experiences of Hindu and Muslim Young Women in Urban Bengaluru. Compare: A Journal of Comparative and International Education. Vol. 47, No. 2. pp. 177-191.

Sarkar, S., Sahoo, S. and Klasen, S. 2019. Employment Transitions of Women in India: A Panel Analysis. World Development. Vol. 115. pp. 291-309.

Shukla, A. 2015. Attitudes towards Role and Status of Women in India: A Comparison of Three Generations of Men and Women. Psychological Studies. Vol. 60, No. 1. pp. 119-128.

Smeby, J.-C. and Try, S. 2005. Departmental Contexts and Faculty Research Activity in Norway. Research in Higher Education. Vol. 46, No. 6. pp. 593-619.

Sorsa, P. 2015. Raising the Economic Participation of Women in India: A New Growth Engine?. OECD Economics Department Working Papers. No. 1185. Paris, OECD Publishing.

Strauss, A. and Corbin, J. 1998. Basics of Qualitative Research Techniques. California, Sage publications.

Suitor, J. J., Mecom, D. and Feld, I. S. 2001. Gender, Household Labor, and Scholarly Productivity among University Professors. Gender Issues. Vol. 19, No. 4. pp. 50-67. 
Thelwall, M., Bailey, C., Makita, M., Sud, P. and Madalli, D. P. 2019. Gender and Research Publishing in India: Uniformly High Inequality?. Journal of Informetrics. Vol. 13, No. 1. pp. 118-131.

Tien, F. F. and Blackburn, R. T. 1996. Faculty Rank System, Research Motivation, and Faculty Research Productivity: Measure Refinement and Theory Testing. Journal of Higher Education. Vol. 67, No. 1. pp. 2-22.

UGC-Report. 2018. Statistics about Indian Educational System. New Delhi, UGC.

UNESCO. 2017. Cracking the code: Girls' and women's education in science, technology, engineering and mathematics (STEM). Paris, UNESCO.

Vlasceanu, L. and Hancean, M.-G. 2015. Policy Incentives and Research Productivity in the Romanian Higher Education. An Institutional Approach. The European Higher Education Area. SpringerLink, pp. 185-203.

Vuong, Q.-H., Ho, T. M., Vuong, T.-T., Napier, N. K., Pham, H. H. and Nguyen, H. V. 2017. Gender, Age, Research Experience, Leading Role and Academic Productivity of Vietnamese Researchers in the Social Sciences and Humanities: Exploring a 2008-2017 Scopus Dataset. European Science Editing. Vol. 43, No. 3. pp. 51-55.

West, J., Jacquet, J., King, M., Correll, S. and Bergstrom, C. 2013. The Role of Gender in Scholarly Authorship. PLOS one. Vol. 8, No. 7.

Willig, C. 2001. Qualitative Research in Psychology: A practical Guide to Theory and Method. Buckingham, OUP.

Wootton, R. 2013. A Simple, Generalizable Method for Measuring Individual Research Productivity and its Use in the Long-term Analysis of Departmental Performance, including Between-country Comparisons. Health Research Policy and Systems. Vol. 11, No. 1. pp. 1-14.

Xie, Y. and Shauman, K. A. 2004. Women in Science: Career Processes and Outcomes. Social Forces. Vol. 82, Vol. 4. pp. 1669-1671. 